\title{
Fide performansı üzerine firma etkisi
}

\section{Company effect on the seedling performance}

\author{
Ahmet Şafak MALTAŞĐ, Süfyan UÇOVA®, Mustafa KAPLANi \\ Akdeniz Üniversitesi, Ziraat Fakültesi, Toprak Bilimi ve Bitki Besleme Bölümü, Antalya, Türkiye \\ Sorumlu yazar (Corresponding author): M. Kaplan, e-posta (e-mail): mkaplan@akdeniz.edu.tr \\ Yazar(lar) e-posta (Author e-mail): ahmetsafak@akdeniz.edu.tr, sufyanucova@hotmail.com, mkaplan@akdeniz.edu.tr
}

\section{MAKALE BİLGİSİ}

Alınıș tarihi 12 Mart 2019

Düzeltilme tarihi 19 Nisan 2019

Kabul tarihi 26 Nisan 2019

\section{Anahtar Kelimeler:}

Domates fidesi

Fide kalitesi

Fide kalite varyasyonu

Firma etkisi

\begin{abstract}
ÖZ
Başarılı bir yetiştiricilikte fide kalitesinin önemli etkisi bilinmesine rağmen, fide kaynakl olabileceğini düşündüğümüz verim ve kalite sorunlarının neden olduğu ekonomik kayıplar devam etmektedir. Bu çalışma, 5 farklı firma tarafından üretilen domates fidelerinin, serada gelişim ve verim performanslarını karşılaştırmak amacı ile yürütülmüştür. Aynı zaman diliminde, aynı çş̧idin tohumlarından elde edilen fideler yaklaşık 8 ay süresince yetiştirilmiştir. Seraya dikim öncesi firmalar arasında değişim aralıkları, fide gövde uzunluğunda $9.80-17.10 \mathrm{~cm}$ ve fide gövde çapında $2.59-3.15 \mathrm{~mm}$ olarak ölçülmüștür. Sera domates gelişimi döneminde belirlenen değerler; ilk salkım yerden yüksekliğinde, 33.30-49.25 $\mathrm{cm}$, 45. gün bitki boyunda, 84.90-100.20 cm, gövde çapında, 11.86-14.10 mm, sezon sonu bitki boyunda, 267.0-298.5 $\mathrm{cm}$ aralığında belirlenmiștir. Firmalar arasındaki 1. kalite meyve verimi ve kalitesi ile ilgili kriterlerde minimum ve maksimum değerler arasındaki yüzde farkların meyve veriminde \%29.6, meyve çapında \%13.1, meyve sayısında \%22.9 ve meyve ağırlığında \%5.4 olduğu tespit edilmiștir. Sonuç olarak; farklı fide firmalarından sağlanan fidelerin üretimdeki performanslarındaki varyasyonun yüksek olduğu görülmektedir. $\mathrm{Bu}$ yüksek varyasyona, fidelerin fiziksel özelliklerindeki farklılığa ek olarak, kimyasal özelliklerindeki olası farklılıkların da etki edebileceği öngörülmelidir. Fideliklerden teslim alınan fidelerin fiziksel özelliklerinin yanı sıra, kimyasal özelliklerinin de belirlenmesi gerekli gözükmektedir. $\mathrm{Bu}$ izleme ve değerlendirme fide üreticilerinin kendilerinin ve rakiplerinin performansını sorgulamalarını sağlayabilecektir. Ayrıca bu değerlendirme sürecinden sonra çiftçiler gerekli doğru bakım uygulamalarını gerçekleștirebileceklerdir. Akademik çalıșmalar ile, fidelerin dikimden sonraki performanslarını etkileyen özellikleriyle ilgili standart değer aralıkları belirleme çalışmalarına olan ihtiyaca vurgu yapmak gerekir. Benzer durumlar, diğer sebze fidelerinde de geçerli olabilir.
\end{abstract}

\section{ARTICLE INFO}

Received 12 March 2019

Received in revised form 19 April 2019

Accepted 26 April 2019

\section{Keywords:}

Tomato seedling

Seedling quality

Seedling quality variation

Company effect

\begin{abstract}
Although it is known that seedling quality has a vital effect in a successful production, economic losses caused by yield and quality problems based on the seedling have going on. This study was conducted to compare growth and yield performances of tomato seedlings produced by 5 different seedling companies in greenhouse. These seedlings belong to same cultivar were grown through 8 months in the same period. Before transplanting the seedlings, stem height, and stem diameter of the seedlings were observed $9.80-17.10 \mathrm{~cm}$ and $2.59-3.15$ $\mathrm{mm}$, respectively. First bunch height $(\mathrm{cm})$, plant height in 45 days $(\mathrm{cm})$, stem diameter $(\mathrm{mm})$ and plant height in last growth stage were also determined $33.30-49.25 \mathrm{~cm}, 84.90-100.20 \mathrm{~cm}$, $11.86-14.10 \mathrm{~mm}$ and $267.0-298.5 \mathrm{~cm}$ during the growth period of tomato. Coefficient of variation $(\%)$ in the criteria related to first class fruit yield and quality between the companies was observed as $29.6 \%$ in fruit yield, $13.1 \%$ in fruit diameter, $22.9 \%$ in number of fruits per plant and $5.4 \%$ in fruit weight per plant. In conclusion, $\mathrm{CV}$ values were found as high for performances of seedlings. It is estimated that these differences among the seedlings can also be affected by chemical properties of the seedlings in addition to differences in physical properties of the seedlings and so these chemical properties of the seedlings should be analyzed. The tracking and evaluation processes may benefit to compare the performances among the seedling producers. Moreover, the farmers can apply better the cultural practices for the seedlings after the tracking and evaluation processes. Lastly, the further studies should be carried out to determine the standard ranges related to the performances of the seedlings in the growth stage. This situation can be valid for other vegetables.
\end{abstract}




\section{Giriş}

Bitkisel üretimde temel hedef, yüksek verimde, kaliteli ve sağlıklı üretim yapmaktır. Son zamanlarda, özellikle örtü altı yetiştiriciliği ve açık tarla koşullarında yetiştirilen sebzelerin büyük bir kısmında üretimin başlangıç materyali olarak hazır fide kullanılmaktadır. Türkiye'de hazır fide üretimi yapan işletmelerde yıllık yaklaşık 2 milyar fide üretilmekte, üretilen fidelerin türlere göre dağılımında da \%41.2 oran ile domates ilk sırada yer almaktadır (Yelboğa 2014; Tüzel ve ark. 2015). Başarılı bir bitkisel üretim için kullanılan fidenin kaliteli olması çok özel bir değere sahiptir. Fide kalitesi olarak; hastalık ve zararlıdan ari, dengeli bir kök/gövde oranı, yüksek kuru madde, iyi gelişmiş bir kök sistemi, hızlı yeni kök oluşturabilme, adaptasyon kabiliyeti, sağlıklı yapraklar ile optimum mineral bitki besin ve karbonhidrat içeriği sayılabilir. Özellikle optimum beslenme düzeyinin olması fide kalitesi olarak değerlendirilen diğer tüm özellikler üzerine etkisi olabilecek bir kriterdir. Yetiştirilen sebze fidelerinin optimum besin içeriğine ve besinler arası dengelere sahip olması, fidelerin yetiştirildiği firmalardaki yetiştirme ortamlarının besleme kapasitesine (Alan 1990; Brohi ve ark. 1995; Doğan 2003; Demir 2017; Sönmez 2017; Yılmaz ve ark. 2017) ve daha çok da fide firmasının yetiştirme süresince uyguladığı besleme programlarına (Dursun ve ark. 2002) bağlıdır. Ayrıca hazır fide üretiminin yapıldığ tesislerde; ortam sıcaklığı yönetimi (Hurd ve Graves 1984; De Konning 1990; Heuvelink 1995; Wang ve ark. 1996; Abe ve ark. 2008; Guan ve ark. 2009) ve 1şı yoğunluğu da (Heuvelink 1989; Uzun 1996; Kevseroğlu 1999; Liu ve ark. 2010) fide gelişimini etkileyen diğer faktörler arasındadır.

Hazır fide üretimi yapan işletmeler ve bu fideleri kullanan üreticilerin fide kalitesini belirlerken çoğunlukla fidelerin fiziksel görünümleri ilgili bazı gözlemlerle yetindikleri düşünülmektedir. Fide işletmelerinin yetiştirme ortamı ve tekniklerine bağlı olarak farklı özelliklerde fide ürettiğine yönelik çalışmalar mevcuttur (Kaplan ve ark. 2016; Maltaş ve ark. 2017). Ayrıca bitkisel üretimde kullanılan fide kalitesinin, meyve verimi ve kalitesini etkilediğine dair çalışmalar bulunmaktadır (Ece ve Ulukan 2011). Bu nedenle maksimum kalite ve verimde bitkisel üretimin hedeflendiği her yetiştiriciliğe; kaliteli bir fide ile başlanması gerekir. Fide yetiştiriciliğinde pek çok farklı uygulamanın fide gelişimi ve kalite kriterleri üzerine etkileri araştırılmış olsa da üreticiler tarafından teslim alınan fidelerin dikildikleri yerlerdeki adaptasyonları ve gelişme performansları üzerine yapılan araştırma sayısı çok sınırlıdır. Bitkisel üretimde kullanılan fideleri sağlama konusunda en çok katkı sunan hazır fide firmalarının etkilerini araştıran çalışma sayısı ise çok daha sınırlıdır. Bu çalışma; farklı fide firmalarından teslim alınan domates fidelerinin bitki gelişimi, meyve verimi ve bazı kalite kriterleri üzerine olan etkilerini ve bu alandaki varyasyonu belirlemek, bu varyasyonun azaltılması yönündeki çalışmalara 1şık tutmak amacıyla yapılmıştır.

\section{Materyal ve Yöntem}

$\mathrm{Bu}$ araştırmada tek mahsül domates yetiştiriciliğinde en çok tercih edilen tanelik domates çeşitlerinden biri olan Bestona $F_{1}$ kullanılmıştır. 5 farklı fide firmasında tohumların aynı gün içerisinde ekilmesi sağlanmıştır. Yetiştirme tekniği olarak fideliklere hiçbir ek müdahalede bulunulmamıştır. Tohum ekimleri aynı gün yapılan fideler, ekimden 40 gün sonra aynı gün teslim alınmıştır. 5 farklı fide firmasının her birinden ayrı ayr1 45 fide tesadüfi olarak seçilmiş ve her firma için fide gövde çap1 ve fide gövde uzunlukları belirlenmiştir. Fide gövde çapı ve fide gövde uzunluğu ölçümü yapılan 45 fideden 30 tanesi tesadüfi olarak seçilmiş ve sonrasında 20/10/16 tarihinde Akdeniz Üniversitesi Ziraat Fakültesi uygulama alanında bulunan cam seraya her tekerrürde 10 adet fide olacak şekilde 3 tekerrürlü dikilmiştir.

Sera toprağının bazı fiziksel ve kimyasal özellikleri Çizelge 1'de verilmiştir. Dikimden sonraki yaklaş1k 8 aylık üretim sezonu (16/06/2017 tarihine kadar) boyunca her parsele bütün kültürel işlemler (sulama, gübreleme, koltuk alma vb.) eşit şekilde yapılmıştır.

Araştırmada farklı fideliklerde üretilen domates fidelerin dikimden sonraki gelişim farklılıklarını kıyaslamak amacı ile fide gövde uzunluğu $(\mathrm{cm})$, fide gövde çapı $(\mathrm{mm})$, ilk salkım yerden yüksekliği $(\mathrm{cm}), 45$. günde bitki boyu $(\mathrm{cm})$, 45. gün gövde çap1, meyve verimi ve kalitesi parametreler ile sezon sonu bitki boyu $(\mathrm{cm})$ değerleri ölçülmüştür.

Çizelge 1. Araştırmada kullanılan deneme toprağının bazı fiziksel ve kimyasal özellikleri.

Table 1. Some physical and chemical properties of soil used in study.

\begin{tabular}{ccc}
\hline Özellikler & Değer & Değerlendirme \\
\hline pH & 7.42 & Hafif alkali \\
Kireç $(\%)$ & 17.2 & Çok fazla kireçli \\
Bünye & - & Killi tın \\
EC $\left(\mathrm{dS} \mathrm{m}^{-1}\right)$ & 0.42 & Tuzsuz \\
Organik Madde (\%) & 2.43 & Az \\
Toplam azot, $(\%)$ & 0.15 & Çok iyi \\
Yarayışlı $\mathrm{P}_{2} \mathrm{O}_{5},(\mathrm{ppm})$ & 236.5 & Yüksek \\
Değişebilir K (ppm) & 568.2 & Yüksek \\
Değişebilir Mg (ppm) & 469.8 & İyi \\
Değişebilir Ca (ppm) & 4259.0 & İyi \\
Değişebilir Na (ppm) & 101.4 & Düşük \\
Fe $(\mathrm{ppm})$ & 4.73 & İyi \\
$\mathrm{Mn}(\mathrm{ppm})$ & 10.7 & Yeterli \\
$\mathrm{Zn}(\mathrm{ppm})$ & 9.24 & İyi \\
Cu (ppm) & 6.8 & Yeterli \\
\hline
\end{tabular}

\section{Bulgular ve Tartışma}

Beş farklı fide işletmelerinde yetiştirilen aynı çeşit domates fidelerinde fide gövde uzunluğu, ilk salkım yerden yüksekliği, 45. gün bitki boyu, sezon sonu bitki boyu, fide gövde çap ve 45 . gün gövde çapı ilgili veriler Çizelge 2'de verilmiştir.

Dikimden önce ölçülen fide gövde uzunlukları ortalama değerleri incelendiğinde, minimum değer $9.80 \mathrm{~cm}$ olarak ölçülürken, maksimum değer $17.10 \mathrm{~cm}$ olarak ölçülmüştür.

Fide firmalarının bitki gelişimi üzerine etkilerini incelemek amacıyla ölçülen minimum ve maksimum değerlerin; ilk salkım yerden yüksekliği $33.3-49.25 \mathrm{~cm}, 45$. günde bitki boyu 84.9 $100.2 \mathrm{~cm}$, sezon sonu bitki boyu $267.0-298.5 \mathrm{~cm}$, fide gövde çap1 2.59-3.15 mm ve 45. gün gövde çap1 11.86-13.00 mm arasında olduğu belirlenmiştir.

Minimum ve maksimum değerler arasında; fide gövde uzunluğunda \%74.48, ilk salkım yerden yüksekliğinde $\% 47.9$, 45. günde bitki boyunda $\% 18.02$, sezon sonu bitki boyunda $\% 3.8$, fide gövde çapında $\% 21.62$ ve 45 . gün gövde çapında $\% 18.99$ fark olduğu tespit edilmiştir.

Domates bitkisinin gelişiminin göstergesi olarak ölçülen kriterler değerlendirildiğinde, başlangıçta tespit edilen fide 
firmalarının yetiştiricilik tekniklerine bağlı olarak fide gövde uzunlukları arasındaki \% farkın; dikimden sonra zamanla azaldığı belirlenmiştir. Hatta başlangıçta yüksek fide boyuna sahip olan fidelerin sezon sonunda daha düşük bitki boyuna sahip olduğu görülmektedir. Bu durum özellikle fide gövde uzunluğunu belirlerken her hazır fide firmasının farklı teknikler uyguladığını göstermektedir (Maltaş ve ark. 2017). Fide boylarında ve çaplarında başlangıçta belirlenen farkların, dikimden sonraki aşamalarda bitki gelişimine, meyve verim ve kalitesine etki edebileceği öngörülebilir. Çünkü fide gövde boyunun özellikle kimyasal yöntemlerle kontrol altına alınması ile fidelerin yeterli kuru madde üretmesi ve yaprak alanı artışında problemler ortaya çıkabilmektedir (Alagöz ve Özer 2017). Nitekim dikimden sonraki aşamalarda ölçülen kriterler incelendiğinde firmalar arasında meyve verimi ve kalitelerinde de farklılıkların olduğu tespit edilmiştir. Firmalar arasındaki fide gövde çapları arasındaki fark (\%21.62) kökler tarafından alınan bitki besin elementleri ve suyun bitkinin diğer kısımlarına (gövde, yaprak ve meyve) taşınmasında rol oynayan önemli bir faktör olarak değerlendirilebilir. Gövde çap1 ve gövde boyunun bitki verimi üzerine etkili olduğu bildirilmektedir (Uzun 2001; Kandemir 2005; Özer 2012; Özer ve Kandemir 2017).

Denemede yetiştirilen domateslere ait meyve verimi ve kalitesi ile ilgili değerler ise Çizelge 3 'de verilmiştir. 1. kalite meyvelere ait ölçülen minimum ve maksimum değerler, ortalama meyve sayısında 48-59 adet bitki ${ }^{-1}$, ortalama meyve çapında 62.60-70.82 mm, ortalama meyve ağırlığında 129-136 $\mathrm{g} \mathrm{meyve}^{-1}$ ve ortalama verimde $6,19-8.02 \mathrm{~kg} \mathrm{bitki}^{-1}$ olarak belirlenmiştir. 2. kalite meyvelerde belirlenen minimum ve maksimum değerler ise, ortalama meyve sayısında 7-20 adet bitki ${ }^{-1}$, ortalama meyve çapında 46.01-49.63 mm, ortalama meyve ağırlığında 40-44 $\mathrm{g}$ meyve $^{-1}$ ve ortalama verimde 0.28 $0.88 \mathrm{~kg}$ bitki olarak tespit edilmiştir.

1. kalite meyvelerde tespit edilen $\%$ farklar ortalama meyve sayısında $\% 22.9$, ortalama meyve çapında $\% 13.1$, ortalama meyve ağırlığında \%5.4 ve ortalama verimde \%29.6 olarak belirlenmiştir. 2. kalite meyvelerde ise ortalama meyve sayısında $\% 185$, ortalama meyve çapında $\% 7.9$, ortalama meyve ağırlığında \%10.0 ve ortalama verimde \%214.0 fark olduğu tespit edilmiştir (Çizelge 3).

Üretici açısından dekara ortalama 2500 bitki dikildiği düşünüldüğünde fide firmalarından kaynaklı sadece 1. kalite $4575 \mathrm{~kg} \mathrm{da}^{-1}$ verim farkı olduğu hesaplanabilir. Bu durum hem üretici hem de ülke ekonomisi açısından engellenebilir bir kayıptır. Maltaş ark. 2017 tarafından yapılan bir çalışmada farklı fide firmalarının üretmiş oldukları fidelerdeki kuru madde miktarları arasında \%21.05 fark olduğu bildirilmiştir. Fidelerdeki kuru madde miktarının özellikle meyve verimi üzerine etkili olduğu pek çok araştırmacı tarafından söylenmiştir (Ece ve Ulukan 2011; Özer ve Kandemir 2017). Ayrıca toplam kuru madde miktarının yanında kuru maddeyi oluşturan bitki besin elementleri arasındaki oranlarında fidelerin performanslarına etki edebileceği söylenebilir (Ünlü ve ark. 2010). Hazır fide üretimi yapan firmalar arasında bitki gelişim düzenleyicileri kullanıp kullanmadıkları bağlı olarak farklılıklar meydana gelebileceği gibi, bitki gelişim düzenleyici kullanan fide firmalarının kullanım dozları ve sıklıkları arasında ki değişiklikler bile fide gelişimine önemli düzeyde etki gösterebilir.

Fideleri satın alan çiftçilerin bazı durumlarda fide gelişimlerini beğenmedikleri ve sonrasında da satın aldıkları fideliklere şikayette bulundukları bilinen bir gerçektir. Şikayetin türüne (fide gelişiminin yavaş olması, hastalıklı fide vb.) ve düzeyine bağlı olarak çiftçiler ile fide firmaları mahkeme yoluna başvuracak düzeyde kalite farklılıklarının olduğu duyulmaktadır. Üretilen fidelerde standardizasyonun olmaması ve dolayısı ile varyasyonun geniş olması çiftçilerin, aynı zamanda fide firmalarının da mağdur olmasına sebep olmaktadır. Fide teslimi sırasında kalite kriterlerinin rakamsallaştırılmaması, standart aralıkların belirlenmemiş olmaması kalite kriterlerindeki büyük varyasyonun temel nedeni olarak görülebilir.

\section{Sonuç}

Bitkisel üretimlerde temel hedef meyve verimi ve kalitesini artırmaktır. Bu amaçla sürekli olarak yenilikler ve optimum koşulların sağlanması için arayışlar söz konusudur. Bu arayışların sonuçlarından birisi olan hazır fide üretimi başlamış ve büyük bir sektör haline gelmiştir. Hazır fide üretiminde kendi içerisinde homojen, kaliteli fide üretimini çoğunlukla sağlamaktadır. Buna bağlı olarak da hazır fide sektörü her geçen gün büyümekte dolayısı ile bu sektörde hizmet veren fidelik sayısı günden güne artmaktadır. Her ne kadar fideliklerde üretilen fideler kendi içerisinde homojen olsalar bile, hazır fide sektöründe üretilen tüm fidelerin de kendi içerisinde makul düzeyde eşit kalite de olması gerekmektedir. Bu çalışmada 5 farklı fidelikten alınan fideler ile eşit koşullarda tek mahsul domates yetiştiriciliği yapılmıştır. Elde edilen hemen hemen bütün sonuçlarda, özellikle de meyve verimi ve kalitesinde tespit edilen minimum ve maksimum farkların daha az olması

Çizelge 2. Fide gövde uzunluğu, fide gövde çapı, ilk salkım yerden yüksekliği, 45. gün bitki boyu, 45. gün gövde çapı ve sezon sonu bitki boylarına ait değerler.

Table 2. Values of Seedling length, seedling diameter, height of the first fuit from the ground, 45 th day plant height, 45 th day plant diameter and end of the season plant length.

\begin{tabular}{|c|c|c|c|c|c|c|}
\hline $\begin{array}{l}\text { Fide } \\
\text { firmaları }\end{array}$ & $\begin{array}{c}\text { Fide gövde } \\
\text { uzunluğu }(\mathrm{cm})\end{array}$ & $\begin{array}{l}\text { İlk salkım yerden } \\
\text { yüksekliği }(\mathrm{cm})\end{array}$ & $\begin{array}{l}\text { 45. günde bitki } \\
\text { boyu }(\mathrm{cm})\end{array}$ & $\begin{array}{l}\text { Sezon sonu bitki } \\
\text { boyu }(\mathrm{cm})\end{array}$ & $\begin{array}{l}\text { Fide gövde çapı } \\
(\mathrm{mm})\end{array}$ & $\begin{array}{l}\text { 45. gün gövde çap1 } \\
(\mathrm{mm})\end{array}$ \\
\hline 1 & 10.17 & 43.15 & 84.90 & 267.0 & 2.75 & 13.40 \\
\hline 2 & 12.06 & 34.35 & 96.90 & 288.0 & 2.59 & 11.86 \\
\hline 3 & 12.03 & 33.30 & 92.30 & 296.6 & 2.86 & 12.76 \\
\hline 4 & 9.80 & 49.25 & 94.55 & 298.5 & 3.15 & 14.10 \\
\hline 5 & 17.10 & 39.90 & 100.2 & 285.16 & 3.02 & 12.97 \\
\hline Minimum & 9.80 & 33.30 & 84.90 & 267.0 & 2.59 & 11.86 \\
\hline Maksimum & 17.10 & 49.25 & 100.20 & 298.5 & 3.15 & 14.10 \\
\hline Ortalama & 12.23 & 39.99 & 93.77 & 287.5 & 2.87 & 13.00 \\
\hline Fark $(\%)$ & 74.48 & 47.9 & 18.02 & 3.8 & 21.62 & 18.88 \\
\hline
\end{tabular}


Çizelge 3. Meyve verimi ve bazı kalite parametrelerine ait değerler. Table 3. Values of fruit yield and some quality parameters.

\begin{tabular}{|c|c|c|c|c|c|c|c|c|}
\hline \multirow[b]{2}{*}{ Fide firmalar1 } & \multicolumn{2}{|c|}{ Verim $\left(\mathrm{kg} \mathrm{bitki}^{-1}\right)$} & \multicolumn{2}{|c|}{ Ortalama Meyve çapı (mm) } & \multicolumn{2}{|c|}{ Ortalama meyve sayısı (adet bitki ${ }^{-1}$ ) } & \multicolumn{2}{|c|}{ Ortalama meyve ağırlığı $\left(\mathrm{g}\right.$ meyve $\left.\mathrm{e}^{-1}\right)$} \\
\hline & 1. Kalite & 2. Kalite & 1. Kalite & 2. Kalite & 1. kalite & 2. kalite & 1. kalite & 2. kalite \\
\hline 1 & 6.38 & 0.44 & 70.82 & 47.63 & 48 & 11 & 133 & 40 \\
\hline 2 & 6.19 & 0.28 & 64.66 & 47.87 & 48 & 7 & 129 & 40 \\
\hline 3 & 7.32 & 0.56 & 64.75 & 49.63 & 55 & 13 & 133 & 43 \\
\hline 4 & 7.34 & 0.88 & 64.83 & 47.01 & 54 & 20 & 136 & 44 \\
\hline 5 & 8.02 & 0.70 & 62.60 & 46.01 & 59 & 17 & 136 & 41 \\
\hline Minimum & 6.19 & 0.28 & 62.60 & 46.01 & 48 & 7 & 129 & 40 \\
\hline
\end{tabular}

gerektiği düşünülmektedir. Fidelerin özellikle dikimden sonraki gelişimine etki eden başlica parametreler (kuru madde, besin elementi içerikleri, besin elementleri arasındaki oranlar) tespit edilmeli ve ölçülen değerlerde firmalar arasında yakın değerlerin olması gerekmektedir. $\mathrm{Bu}$ kapsamda fidelerin dikimden sonraki performanslarını etkileyen özellikler için belirli standart değer aralıkları belirlenmeli ve fide firmalarının bu aralıklarda hazır fide üretimi yapmaları sağlanmalıdır. Ayrıca, firmalarının fidelerdeki adaptasyon ve gelişim performansını etkileyecek olan kriterlerdeki düzeyleri fide tesliminden önce belirlemesinin diğer bazı faydaları da bulunabilir. Standart değer aralıkları dışında bir fide üretim meydana gelmiş ise, belirlenen kriter veya kriterlerdeki düşük ya da yüksek içeriklerin nasıl yönetilmesi gerektiği ile ilgili dikimden önce üreticilere teknik destek verilmesi faydalı olabilecektir. Benzer öneriler hazır fide ile üretilen domates dışındaki diğer bitkiler içinde söylenebilir.

Sonuç olarak, ya standart değerler arasında üretim yapılarak fide firmaları arasındaki farklılıklar azaltılmalı ya da fide firmalarından elde edilen fidelerin özellikleri iyi belirlenmeli ve belirlenen fide özelliklerine uygun yetiştirme tekniği ile üretime başlanmalı ve devam edilmelidir.

\section{Kaynaklar}

Abe M, Kurashima A, Maegawa M (2008) Temperature requirements for seed germination and seedling growth of Zostera marina from central Japan. Fisheries Science 74 (3): 589-593.

Alagöz G, Özer H (2017) Domateste farklı fide yetiştirme yöntemlerinin kaliteye etkisi. Akademik Ziraat Dergisi 6: 17-22.

Alan R (1990) Serada Kullanılan Bazı Yetiştirme Ortamları ve Özellikleri. 5. Türkiye Seracılık Sempozyumu. İzmir, Türkiye s. 17-19.

Brohı AR, Karaman MR, Sağlam N, Aktaş A (1995) Biber Fidelerinin Gelişimi Ve Bitki Besin Maddesi İçeriklerine Değişik Harç Ortamlarının Etkisi. Gaziosmanpaşa Üniversitesi Ziraat Fakültesi Dergisi 12: 237-244.

De Koning ANM (1990) Long-term temperature integration of tomato. Growth and development under alternating temperature regimes. Scientia Horticulturae 45(1-2): 117-127.

Demir H (2017) Kullanılmış mantar kompostunun biber fidelerinin büyüme ve bitki besin elementi içeriklerine etkileri. Akdeniz Üniversitesi Ziraat Fakültesi Dergisi 30(2): 91-96.

Doğan D (2003) Domates ve hıyar fidesi üretiminde yetiştirme ortamlarına katılan tavuk gübresinin fide gelişimi ve kalitesine etkileri. Yüksek Lisans Tezi, Fen Bilimleri Enstitüsü, Antalya.

Dursun A, Güvenç I, Turan M (2002) Effects of different levels of humic acid on seedling growth and macro and micronutrient contents of tomato and eggplant. Acta Agrobotanica 55(2): 81-88.
Ece A, Ulukan İ (2011) Doğu Anadolu Bölgesinde Bulunan Bazı Torf Materyallerinin Domateste Fide Kalitesi ve Verim Özelliklerine Etkilerinin Belirlenmesi. Bahçe 40(1): 1-7.

Guan YJ, Hu J, Wang XJ, Shao CX (2009) Seed priming with chitosan improves maize germination and seedling growth in relation to physiological changes under low temperature stress. Journal of Zhejiang University-Science 10(6): 427-433.

Heuvelink E (1989) Influence of day and night temperature on the growth of young tomato plants. Scientia Horticulturae 38: 11-22.

Heuvelink E (1995) Growth, development and yield of a tomato crop: periodic destructive measurements in a greenhouse. Scientia horticulturae 61(1): 77-99.

Hurd RG, Graves CJ (1984) The influence of different temperature patterns having the same integral on the earliness and yield of tomatoes. In III International Symposium on Energy in Protected Cultivation 148: 547-554.

Kandemir D (2005) Sera Şartlarında Sıcaklık ve Ișığın Biber'de (Capsicum annum L.) Büyüme, Gelişme ve Verim Üzerine Kantitatif Etkileri. Doktora Tezi, Ondokuz Mayıs Üniversitesi Fen Bilimleri Enstitüsü, Samsun, s. 149.

Kaplan M, Maltas AS, Hiz A (2016) Determination of Copper Content in Tomato (Solanum Lycopersicum L.) Seedlings Obtained from Five Different Companies. 2nd International Conference on Science, Ecology and Technology Barcelona/Spain, pp. 737-741.

Kevseroğlu K (1999) Bitki Ekolojisi. Ondokuz Mayıs Üniv. Ziraat Fak. Ders Kitab1, Samsun.

Liu X, Xu Z, Chang T, Guo S (2010) Growth and photosynthesis of cherry tomato seedling exposed to different low light of LED light quality. Acta Botanica Boreali-Occidentalia Sinica 30(4): 725-732.

Maltaş AŞ, Hız A, Kaplan M (2017) Fide Kalitesi Üzerine Firma ve Çeşit Etkisi. Akademia Mühendislik ve Fen Bilimleri Dergisi 3: 4854.

Özer H (2012) Organik Domates (Solanum lycopersicum L.) Yetiştiriciliğinde Değişik Masura, Malç Tipi ve Organik Gübrelerin Büyüme, Gelişme, Verim ve Kalite Üzerine Etkileri. Doktora Tezi, Ondokuz Mayıs Üniversitesi Fen Bilimleri Enstitüsü, Samsun.

Özer H, Kandemir D (2017) Domates Yetiştiriciliğinde Koltuk Sürgünleri ile Üretilen Fidelerin Büyüme, Gelişme ve Verime Etkisi. Yyü Tar Bil Dergisi, 27: 165-171.

Sönmez İ (2017) Atık mantar kompostunun domates fidelerinin gelişimi ve besin içerikleri üzerine olan etkilerinin belirlenmesi, Akdeniz Üniversitesi Ziraat Fakültesi Dergisi, 30: 59-63.

Tüzel Y, Gül A, Daşgan HY, Öztekin GB, Engindemiz S, Boyacı HF (2015) Örtüaltı yetiştiriciliğinde değişimler ve yeni arayışlar. Türkiye Ziraat Mühendisliği VIII. Teknik kongresi, Ankara, s.685709.

Uzun S (1996) The quantitative effects of temperature and light environment on the growth, development and yield of tomato 
(Lysopersicon esculentum, Mill) and aubergine (Solanum melongena L.) (Doctoral dissertation, University of Reading).

Uzun S (2001) Serada Domates ve Patlıcan Yetiştiriciliğinin Bazı Büyüme ve Verim Parametreleri İle Sıcaklık ve Iș̣k Arasındaki İlişkileri. 6. Ulusal Seracılık Sempozyumu, Muğla, s. 85-90.

Ünlü H, Ünlü H, Karakurt Y, Padem H (2010) pH Nitrogen and Calcium Concentration Affect Germination and Seedling Growth In Pepper (Capsicum annuum L.) Erciyes Üniversitesi Fen Bilimleri Enstitüsü Dergisi 26: 270-282.
Wang X, Li S, Dong H, Gao Z, Dai S (1996) Effect of low temperature stress on several properties of tomato during seedling and florescence. Acta Horticulturae Sinica 23: 349-354.

Yelboğa K (2014) Tarımın Büyüyen Gücü: Fide Sektörü. Bahçe Haber 3: 13-16.

Yilmaz E, Özen N, Özen MÖ (2017) Determination of changes in yield and quality of tomato seedlings (Solanum lycopersicon cv. Sedef F1) in different soilless growing media. Akdeniz Üniversitesi Ziraat Fakültesi Dergisi 30: 163-168. 